\title{
A Comparative Study On McPherson Strut Suspension System And Double Wishbone Suspension System
}

\author{
Master. Deshmukh Sanket Tushar \\ Department of Mechanical Engineering, S. H. H. J. B. Polytechnic, Chandwad, Dist. Nashik, \\ Maharashtra, India. sanketdeshmukh272727@gmail.com
}

\begin{abstract}
Now a days, the two most commonly used suspension system in automobiles are the McPherson Strut Suspension System and Double Wishbone Suspension System. A vehicle is provided with the suspension system in order to provide a comfortable ride to the passengers and to avoid additional stresses in the vehicle frame. This paper contains the comparative study between McPherson Strut Suspension System and Double Wishbone Suspension System. The comparison is obtained by considering various parameters like Basic differences of the system their Geometry, Kinematic Analysis, ANSYS Simulation which includes structural analysis with static and dynamic loading, Graphical representation of Wheel position vs Camber.
\end{abstract}

Key words - Stresses, Comparative study, McPherson Strut Suspension System, Double Wishbone Suspension System, Geometry, Kinematic Analysis, ANSYS Simulation, Static loading, Dynamic loading, Graphical representation, Wheel position, Camber.

\section{INTRODUCTION}

\section{McPherson Strut Suspension System -}

McPherson strut is a type of independent suspension system. In this type, only lower wishbones are used as shown in figure. This system consists of a telescopic strut shock absorber, a single arm, spring and a diagonal stay. A helical compression spring with a shock absorber surround the upper part of strut. The upper end of the strut is fixed to the underside of the cross member. The lower part of the strut also carries the stub axle, on which the wheel is mounted. The rotary motion of the steering wheel is transmitted to the lower part of the strut. The wishbone is hinged to the cross member and positions the wheel as well as resists the accelerating, braking and the side forces. The system is simple, lighter and keeping the unsprung weight of the vehicle lower. Further the camber also does not change when the wheels move up and down. This type of suspension system provides maximum area in the engine compartment and is therefore, commonly used in front wheel drive cars.

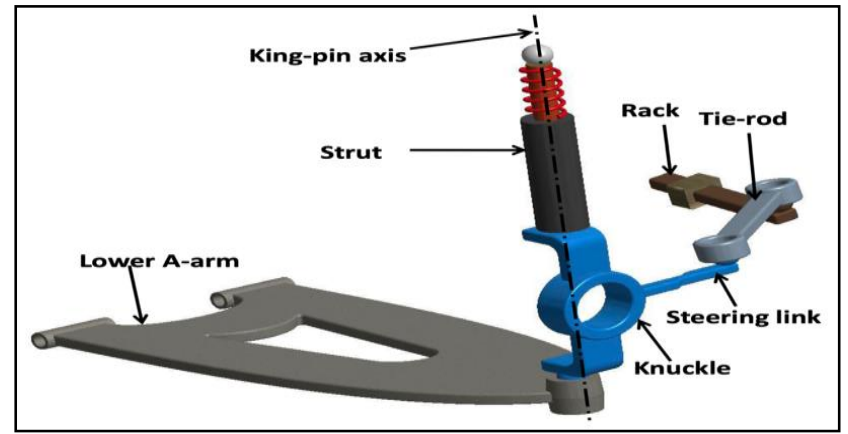

Fig1.1: Solid Model of McPherson Strut Suspension System

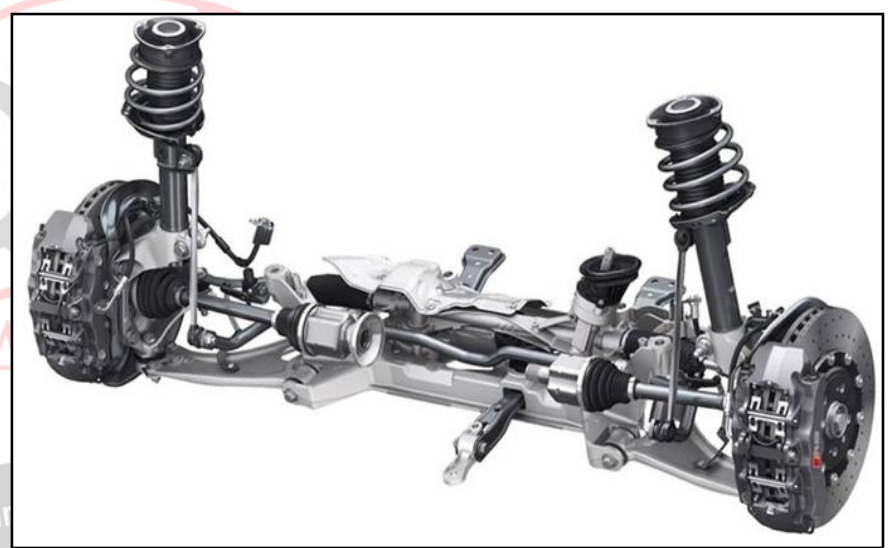

Fig1.2: Actual Set-up of McPherson Strut Suspension System

Double Wishbone Suspension System -

It consists of two wishbone arms pivoted to the frame. The upper wishbone arm is shorter in length than the lower wishbone arm. This helps to keep the wheel track constant, so avoid the tyre scrub and thus reduces the tyre wear. A small change in camber occur in such arrangement. The wishbone type independent suspension system is most popular. The coil spring is located between the lower wishbone and the underside of the upper wishbone of the cross member. The weight of the vehicle is transmitted from the body and the cross members to the coil spring through which it goes to the lower wishbone member. A shock absorber is placed inside the coil spring and is attached to the cross member and to the lower wishbone. Because of ' $\mathrm{V}$ ' shape of arm, the wishbones not only position the wheels and transmits the vehicle load to the spring, but these also resist the acceleration, braking and 
side forces. When the vehicle comes across the bump and the wheel is tended to move up the lower and upper arm moves up and the coil spring is compressed so the shock absorber damps the vibrations set up in the coil spring due to road irregularities.

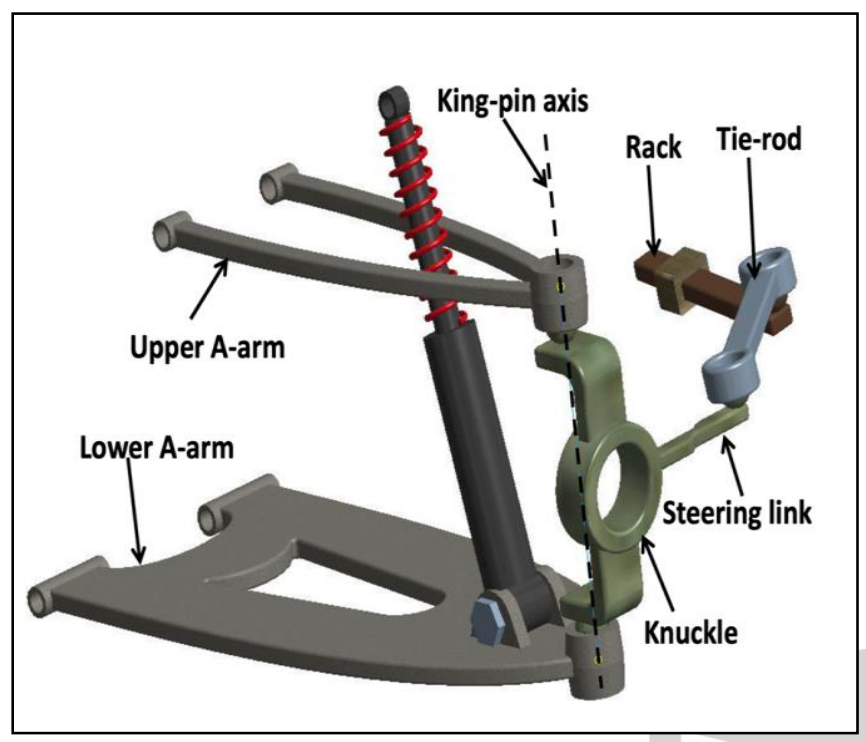

Fig1.3: Solid Model of Double Wishbone Suspension System

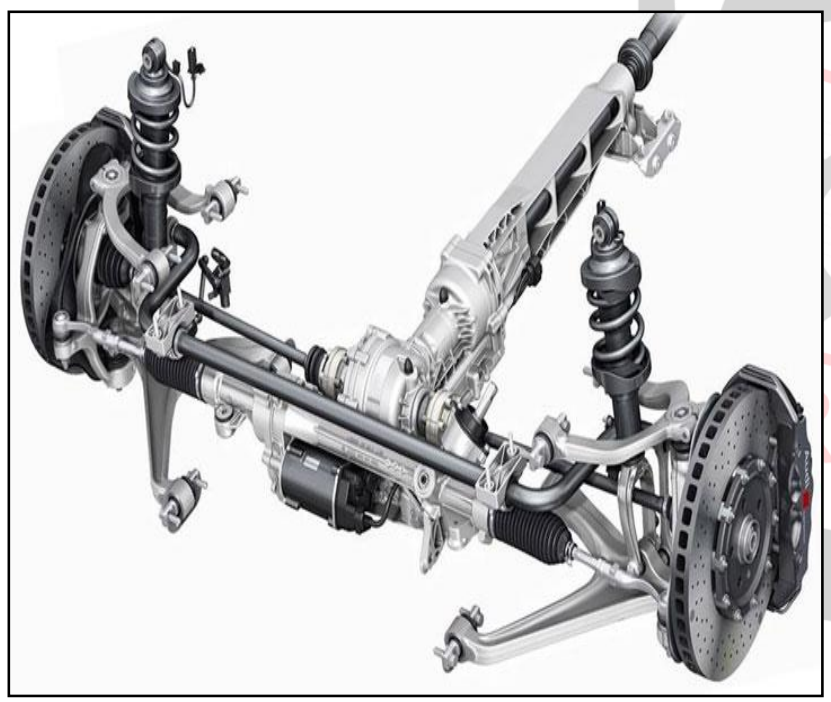

Fig1.4: Actual Set-up of Double Wishbone Suspension System

\section{KINEMATIC ANALYSIS}

The below figures (Fig $2.1 \& 2.2$ ) shows the schematic mechanism McPherson Strut Suspension System and Double Wishbone Suspension System respectively. The success of any mechanism depends upon the kinematic modeling, effective formulation and efficient solving techniques. Kinematically, both the mechanisms are the combination of two spatial mechanisms, a four bar (an inverted slider mechanism) and a five-bar loop. These mechanisms contain or possesses two degrees of freedom one is the steering input $s$ and the other is the jounce or rebound as the road profile input $y$. Thereby determining the output i.e. location and orientation of the King-pin Inclination (KPA) from the combination of calculation the inputs $s$ and $y$.

\section{McPherson Strut Suspension System -}

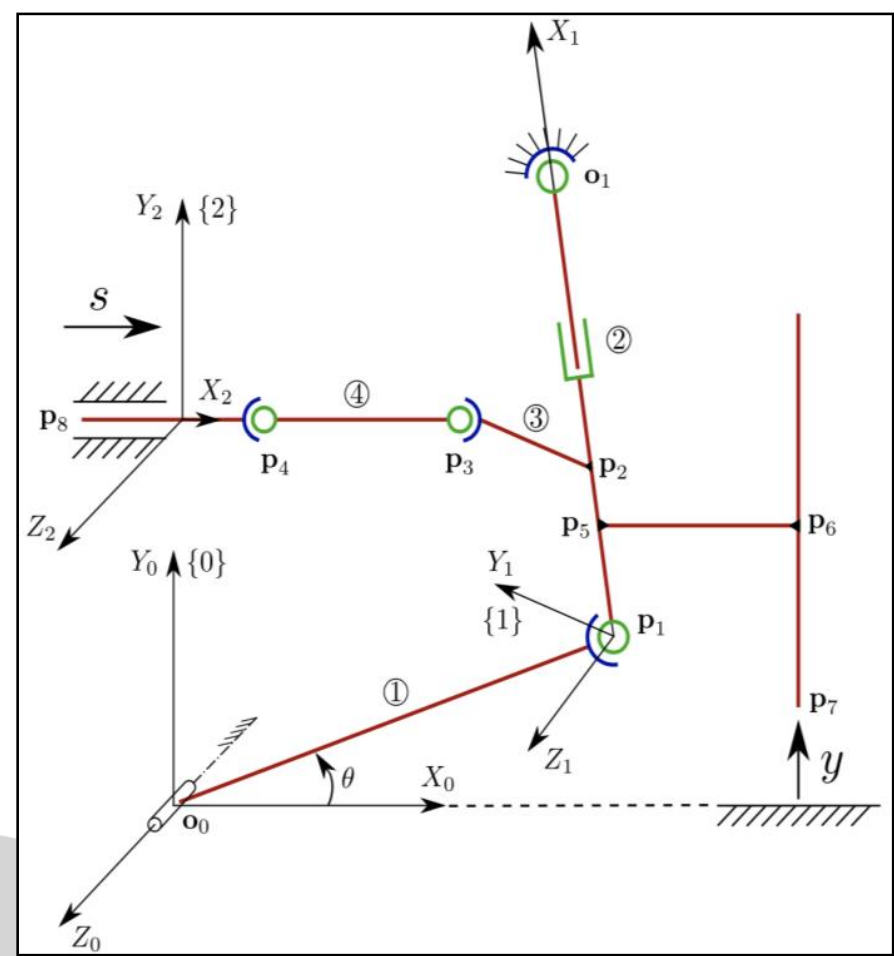

Fig2.1: Schematic of McPherson Strut Suspension System Mechanism

Double Wishbone Suspension System -

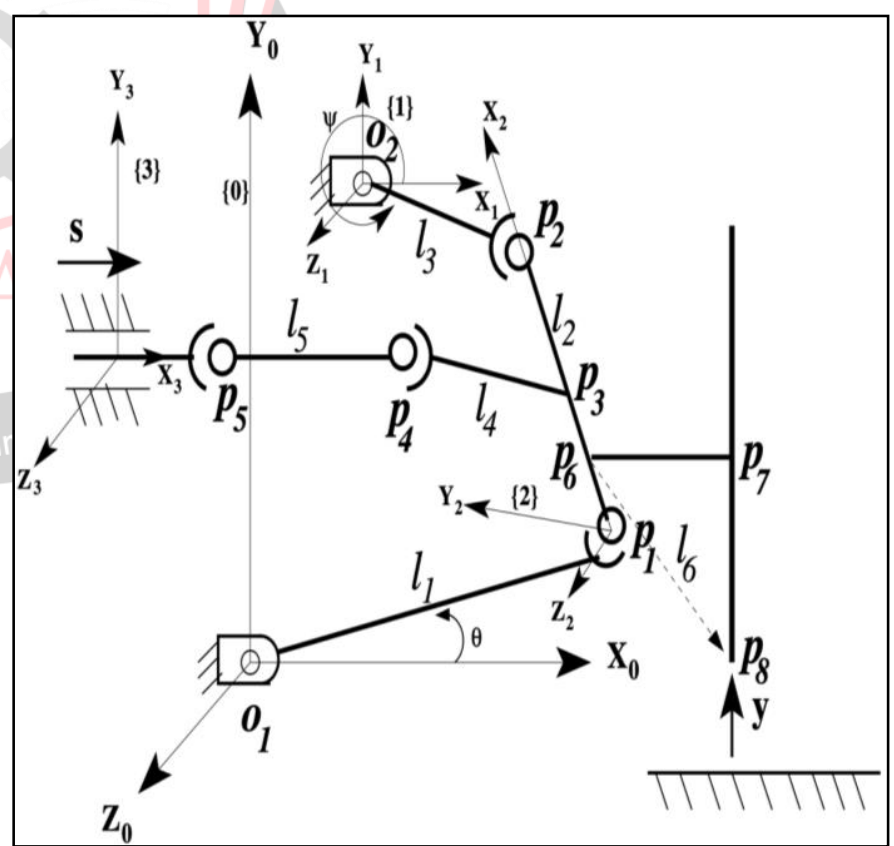

Fig2.2: Schematic of McPherson Strut Suspension System Mechanism

Where,

$\mathrm{P}=$ Point of intersection of Linkages.

$\mathrm{X}, \mathrm{Y}, \mathrm{Z}=$ Principal Axes.

$\mathrm{O}=$ Origin of Kinematic Chains.

$s=$ Steering Input.

$y=$ Road Profile Input. 
III.

\section{ANSYS ANALYSIS FOR VALID ATION \\ UNDER STATIC AND DYNAMIC \\ LOADING:}

Structural Analysis under Static Loading

\section{McPherson Strut Suspension System -}
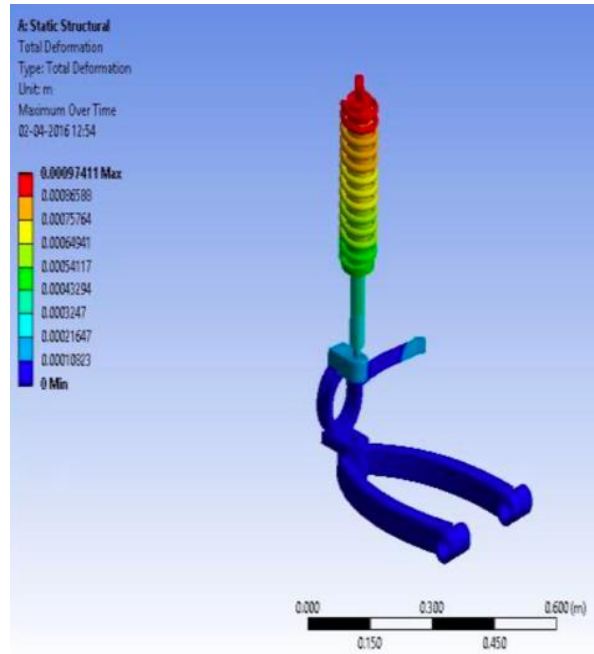

Fig 3.1 Double Wishbone Suspension System -

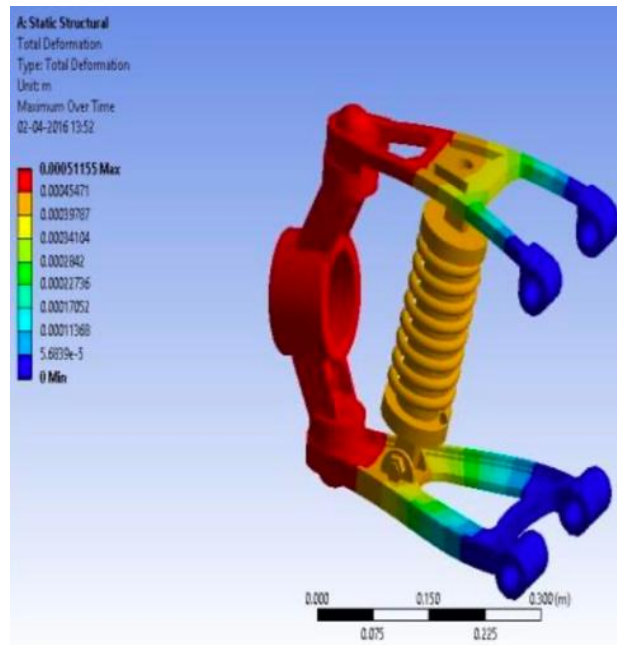

Fig 3.2 Structural Analysis under Dynamic Loading

\section{McPherson Strut Suspension System -}

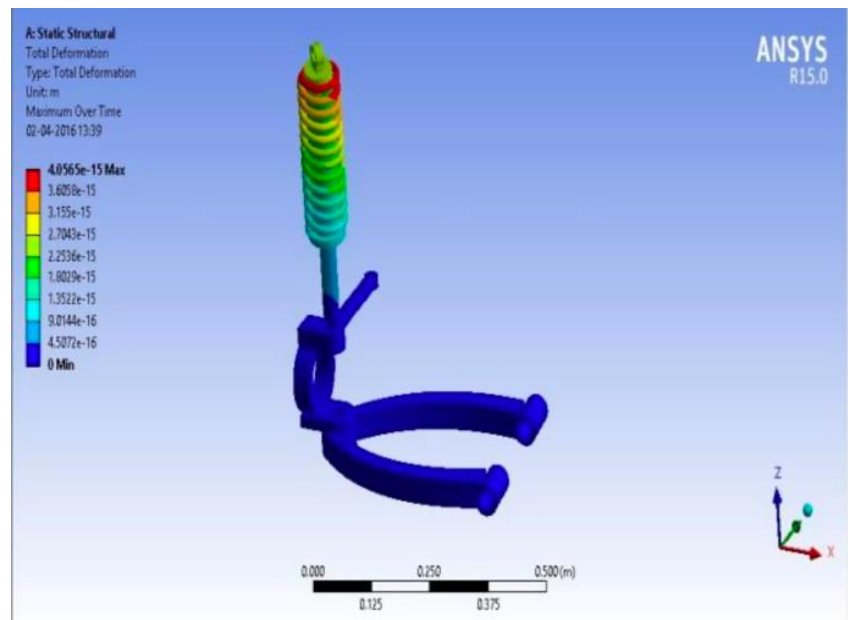

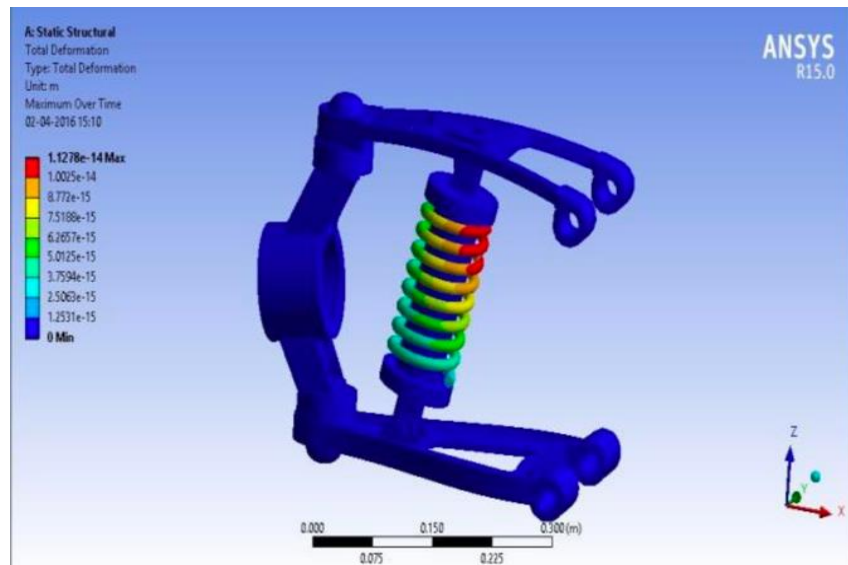

Fig 3.4Transient Analysis

McPherson Strut Suspension System -

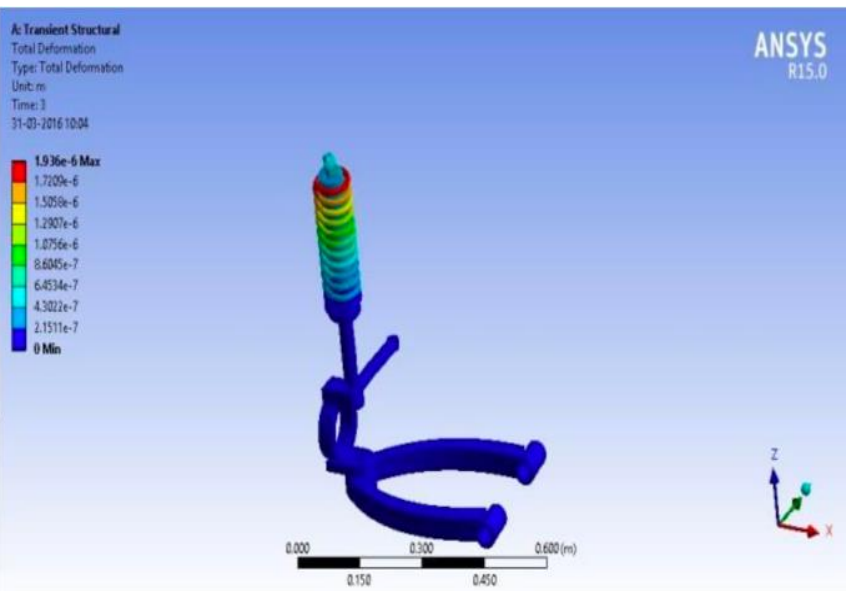

Fig 3.5Double Wishbone Suspension System -

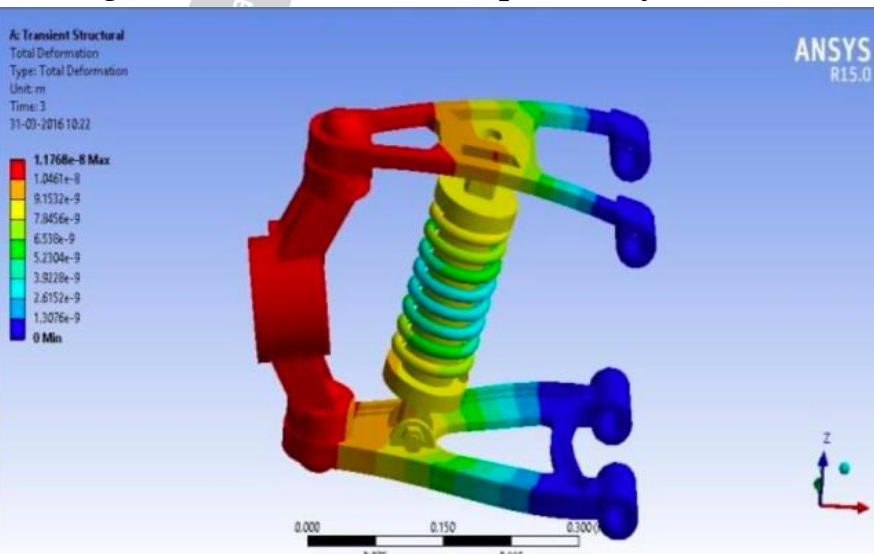

Fig 3.6

IV. RESULT ANALYSIS FROM THE ANSYS SIMULATION

The below table shows the comparison of static structural analysis under the static loading -

\begin{tabular}{|c|c|c|}
\hline Name & Macpherson Suspension & Double wishbone Suspension \\
\hline Deformation $(\mathrm{m})$ & 0.0009471 & 0.00051155 \\
\hline Maximum Principal strain $(\mathrm{m} / \mathrm{m})$ & 0.0003215 & 0.00077035 \\
\hline Equivalent Strain $(\mathrm{m} / \mathrm{m})$ & 0.0010056 & 0.00081165 \\
\hline Von-Misses stress $\left(\mathrm{N} / \mathrm{m}^{2}\right)$ & $1.9991 \times 10^{8}$ & $1.5878 \times 10^{8}$ \\
\hline
\end{tabular}

Table 4.1

Fig 3.3Double Wishbone Suspension System - 
The below table shows the comparison of static structural analysis under the dynamic loading -

\begin{tabular}{|c|c|c|}
\hline Name & Macpherson & Double wishbone \\
\hline Deformation $(\mathrm{m})$ & $4.0565 \times 10^{-15}$ & $1.1278 \times 10^{-14}$ \\
\hline Maximum Principal strain $(\mathrm{m} / \mathrm{m})$ & $1.2039 \times 10^{-13}$ & $1.8625 \times 10^{-13}$ \\
\hline Equivalent Strain $(\mathrm{m} / \mathrm{m})$ & $2.1873 \times 10^{-13}$ & $3.4973 \times 10^{-13}$ \\
\hline Von-Misses stress $\left(\mathrm{N} / \mathrm{m}^{2}\right)$ & 0.025482 & 0.034889 \\
\hline
\end{tabular}

Table 4.2

The below table shows the comparison of transient analysis -

\begin{tabular}{|l|c|c|}
\hline \multicolumn{1}{|c|}{ Name } & Macpherson suspension & Double wishbone suspension \\
\hline Deformation $(\mathrm{m})$ & $1.936 \times 10^{-6}$ & $1.1768 \times 10^{-8}$ \\
\hline Principal strain $(\mathrm{m} / \mathrm{m})$ & $1.3304 \times 10^{-6}$ & $2.9932 \times 10^{-7}$ \\
\hline Equivalent Strain $(\mathrm{m} / \mathrm{m})$ & $1.2795 \times 10^{-6}$ & $7.4066 \times 10^{-7}$ \\
\hline Von-Misses stress $\left(\mathrm{N} / \mathrm{m}^{2}\right)$ & $2.4585 \times 10^{5}$ & $1.0068 \times 10^{5}$ \\
\hline
\end{tabular}

Table 4.3

\section{GRAPHICAL REPRESENTATION OF WHEEL POSITION VS CAMBER}

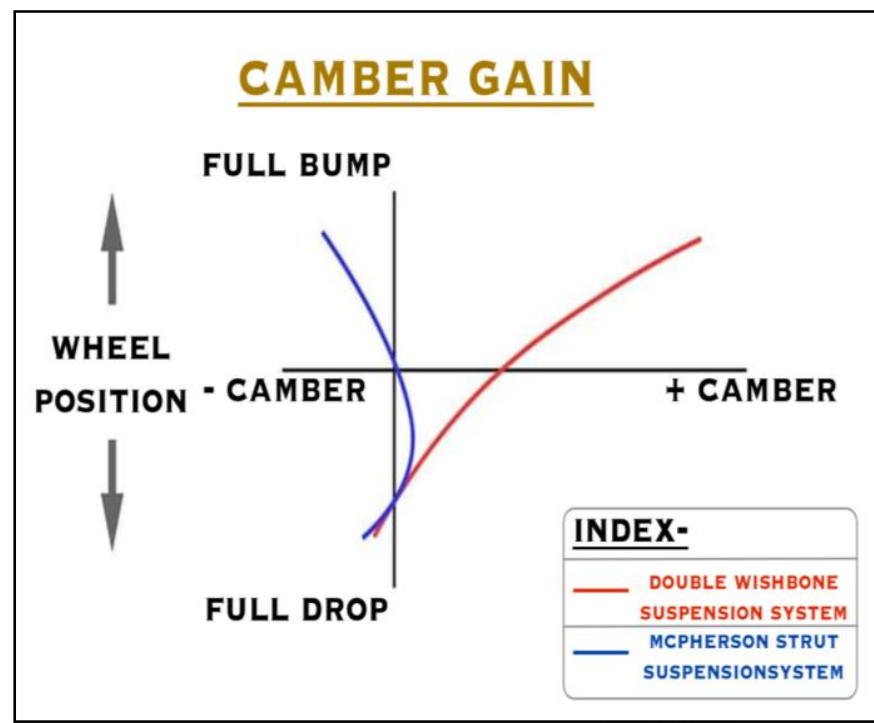

Fig 5.1

The above graph shows the representation of the wheel position against the camber angle. The key advantage of the Double Wishbone type suspension against the McPherson Strut suspension system is that, it gains negative (- ve) camber as the suspension gets compressed. This means that it can run less camber at ride height for better traction and braking for the same cornering effect as that of the McPherson Strut. Thus, the Double Wishbone type suspension is more effective than the McPherson Strut suspension system hence popularly used in the sporty and racing cars.

\section{APPLICATIONS IN AUTOMOBILES}

\section{McPherson Strut Suspension System -}

1. Honda Accord.

2. Honda Civic.

3. Mercedes Benz E-Class.

4. Jaguar XE.

5. Golf GTI.

6. BMW Z4.
7. Porsche Cayenne, etc.

Double Wishbone Suspension System -

1. Alfa Romeo Giulia 952.

2. Lancia Delta S4.

3. Mercedes Benz Top End Models.

4. Toyota Tundra.

5. MG Rover TF.

6. Aston Martin DB7.

7. Lamborghini Aventador 6.5 V12 SV

\section{CONCLUSION}

The above paper possesses a comparative study between the McPherson Strut Suspension System and Double Wishbone Suspension System by considering the both under various parameters in Analysis and validation under different objectives. Thus, making a result that the Double Wishbone Suspension System is quite stable and more advanced as compared to the McPherson Strut Suspension System. This two-suspension system both have different areas of application, considering the McPherson Strut Suspension System is most commonly used in the Front Wheel Drive cars as the system is more compact as compared to the Double Wishbone Suspension System which provides more space for engine compartment. Considering the Double Wishbone Suspension System, it is used in high performance cars and sporty sedans. Considering the cost parameter, the Double Wishbone Suspension System is more expensive as compared to the McPherson Strut Suspension System.

Considering the Equivalent Strain and Von-Mises Stress under the static loading and in the transient analysis in the McPherson Strut suspension system is more as compared to the Double Wishbone type suspension. Hence Failure chances of McPherson Strut suspension system is more as compared to the Double Wishbone type suspension. But considering the Equivalent Strain and Von-Mises Stress under the static loading in the Double Wishbone type suspension is more as compared to the McPherson Strut suspension system. Hence Failure chances of Double Wishbone type suspension is more as compared to the McPherson Strut suspension system.

Thus, from all the above conclusion we conclude that the McPherson Strut Suspension System is more reliable and effective as compared to the Double Wishbone type suspension.

\section{REFERENCES}

[1] Comparative_study_between_double_wishbone_and_mac.pdf (https://iopscience.iop.org/article/10.1088/1757899X/263/6/062079/pdf)

[2] A Text Book Of Automobile Engineering By R. K. Rajput. 
[3] https://cartreatments.com/pros-and-cons-ofmacpherson-vs-double-wishbone-suspension/

[4] https://www.researchgate.net/publication/258683057_S tudy_on_Dynamic_Behaviour_of_Wishbone_Suspensi on_System/link/5854ce8608ae81995eb1d835/downloa d

[5] https://www.researchgate.net/publication/289469869 Kinematic_analysis_of_MacPherson_strut_suspension _system/link/568cf54a08ae71d5cd06f78e/download

[6] Design of Machine Elements By V. B. Bhandari.

[7] https://www.ijates.com/images/short_pdf/1409162782_ P488-493.pdf

[8] https://www.researchgate.net/profile/Sandipan_Bandyo padhyay/publication/289469773_Kinematic_Analysis_ of_the_Double_Wishbone_Suspension_System/links/5 68cf2a108ae197e426ac5e0/Kinematic-Analysis-of-theDouble-Wishbone-Suspension-

System.pdf?origin=publication_detail

[9] https://www.researchgate.net/profile/Dhara_Vadodaria/ publication/267039685_DESIGN_AND_CALCULATI ON_OF_MCPHERSON_SUSPENSION_SYSTEM_A ND_MODIFIED_SUSPENSION_SYSTEM_AND_IT S_COMPARISON/links/5443a46e0cf2e6f0c0fb514a/D ESIGN-AND-CALCULATION-OF-MCPHERSONSUSPENSION-SYSTEM-AND-MODIFIEDSUSPENSION-SYSTEM-AND-ITS-

COMPARISON.pdf?origin=publication_detail

[10] https://pdfs.semanticscholar.org/b467/c46cb98467dc92 3441ced10f5e4c62be5775.pdf

\section{BIOGRAPHIES}

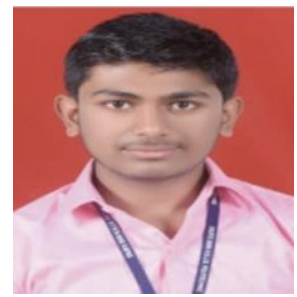

Master. Sanket Tushar Deshmukh perceiving Diploma in Mechanical Engineering (Third Year) from S. H. H. J. B. Polytechnic, Chandwad, Dist. Nashik. 